\title{
Comparison of the Secondary Products Obtained by the Optical Sensor Installed at the Satellite "Resurs-P" with the Products of the Analogous Optical Sensors
}

\author{
S. V. Fedorov \\ Marine Hydrophysical Institute, Russian Academy of Sciences, Sevastopol, Russian Federation \\ e-mail: s.fedorov@mhi-ras.ru
}

\begin{abstract}
Characteristics of the wide-swath multi-spectral equipment with high-resolution (WSME-HR) installed at the Russian Resurs-P type satellites are represented. The possibility of applying the data obtained by this sensor for solving the satellite hydrophysics problems is considered. The chlorophyll $a$ concentration and the normalized water-leaving radiance calculated by the Earth operational monitoring scientific center JSC Russian Space Systems are compared with the similar products of the foreign optical sensors MODIS (Aqua and Terra) and OLI (Landsat-8). Being analyzed, the normalized water-leaving radiance spectra show the values retrieved from the WSME-HR data to be about two times higher in the red spectral range and by 15-20\% smaller in the green spectral range than the analogous ones resulted from the foreign sensors; whereas in the blue spectral range they do not reproduce both their typical maximum on the $488 \mathrm{~nm}$ wavelength and their decrease accompanying the dissolved colored organic matter absorption at the 412 and $443 \mathrm{~nm}$. The chlorophyll $a$ concentration values derived from the data of all the sensors are comparable with each other. This fact is explained by minimum differences between the values of the normalized waterleaving radiance at the 488 and $555 \mathrm{~nm}$ applied for calculating the chlorophyll $a$ concentration.
\end{abstract}

Keywords: optical multi-spectral sensor, chlorophyll- $a$ concentration, normalized water-leaving radiance, WSME-HR, Resurs-P, MODIS, OLI.

Acknowledgements. The work was carried out within the framework of the State Order No. 08272014-0011 Research of the Regularities of Changes in the Condition of the Marine Environment on the Basis of Operational Observations and Data of the System of Diagnosis, Prognosis and Reanalysis of the Condition of Marine Areas (R\&D 115061510036).

For citation: Fedorov, S.V., 2018. Comparison of the Secondary Products Obtained by the Optical Sensor Installed at the Satellite "Resurs-P" with the Products of the Analogous Optical Sensors. Physical Oceanography, [e-journal] 25(1), pp. 27-35. doi: 10.22449/1573-160X-2018-1-27-35

DOI: $10.22449 / 1573-160 \mathrm{X}-2018-1-27-35$

(c) 2018, S. V. Fedorov

(C) 2018, Physical Oceanography

\section{Introduction}

Currently, the Russian remote sensing satellite grouping of eight spacecraft equipped with optical scanners of various spatial and spectral resolution. Its development strategy in 2016-2020 provides for an increase in the number of satellites up to 20. It will give the possibility to carry out the reflected radiance measuring with high spatial and temporal resolution. Data of the Russian satellite optical scanners is used in cartography, forestry, monitoring of emergency situations and in other areas, but it has still no wide application in the field of oceanology and satellite hydrophysics.

The Resurs-P satellites are aimed to study natural resources and monitor emergencies. That is the very reason for significant difference between their optical instruments in the number of spectral channels and their width from specialized 
ocean color scanners. However, to determine the bio-optical parameters of coastal waters, estuaries, lakes and rivers, when high spatial resolution is required that is not available for modern ocean color scanners, optical scanners for terrestrial monitoring are successfully applied, for example ETM+ and OLI scanners on Landsat-7 and Landsat-8 [1-5], WVC and CZI scanners on the Chinese HJ-1 and HY-1 mini satellites $[6,7]$. Such positive experience permits to assume that the data of multispectral Resource-P scanners can be successfully used for solving such problems.

The operator of the Russian space remote sensing systems is the Research Center for Earth Operative Monitoring (NTs OMZ) of JSC Russian Space Systems, which plans the surveys and provides information to customers. In addition to these standard processing levels, NTs OMZ provides a number of secondary products for various applications (agriculture, nature management, ecology, etc.). These products can be ordered through the Basic Products Bank (BPB) (URL: http://bbp.ntsomz.ru) $[8,9]$. Their set differs depending on the purpose and spectral range of measurements of the optical sensors.

The following secondary products characterizing the optical properties of water are of the greatest interest for the problems of oceanology and satellite hydrophysics: the normalized water-leaving radiance $n L_{\mathrm{w}}(\lambda)$; the chlorophyll $a$ concentration $C_{a}$; concentration of dissolved organic carbon DOC; concentration of total suspended matter TSM; photosynthetically active radiation $P A R$; the diffuse attenuation coefficient; the Secchi disc depth, etc. This set of secondary products with a spatial resolution of $100 \times 100 \mathrm{~m}$ was obtained by the NTs OMZ based on the data of measurements of the wide-swath multi-spectral equipment with highresolution (WSME-HR) installed at the Russian Resurs- $P$ type satellites [10].

In the present paper, the following two secondary products are analyzed: the normalized water-leaving radiance $n L_{\mathrm{w}}(\lambda)$, through which other satellite products are usually calculated, and the chlorophyll $a C_{a}$ concentration, which is an important indicator of bioproductivity. The analysis is carried out by comparing the secondary products of $C_{a}$ and $n L_{\mathrm{w}}(\lambda)$, obtained from the WSME-HR measurements, with similar products from foreign optical sensors (MODIS/Aqua, MODIS/Terra and OLI/Landsat-8).

\section{Materials and Methods}

To compare the secondary products, the image of the Black Sea area near Novorossiysk and Gelendzhik made by the WSME-HR sensor on the Resurs-P satellite was used (Fig. 1). WSME-HR allows measuring the brightness of radiation in five spectral channels $(0,43 . .0,51 ; 0,51 \ldots 0,58 ; 0,60 \ldots 0,70 ; 0,70 \ldots 0,90$; $0,80 \ldots 0,90 \mu \mathrm{m})$ with a spatial resolution of $24 \mathrm{~m}$ and in panchromatic mode $12 \mathrm{~m}$. To provide a high level of the signal-to-noise ratio in WSME-HR, the survey technique with variable exposure time is used. Its value depends on the sensitivity of spectral channels, the Sun and viewing geometry from the underlying surface albedo [10].

The revisit rate is one time per three days. The joint use of three Resurs- $P$ satellites currently in orbit allows obtaining high spatial resolution data at least once a day, which is of particular interest for monitoring of the coastal waters, estuaries, lakes and rivers. 


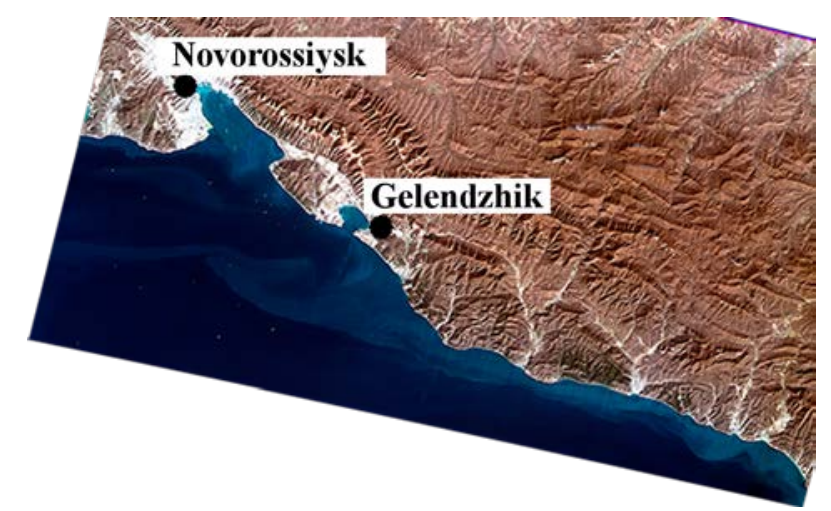

Fig. 1. WSME-HR true-color image fragment

The normalized water-leaving radiance $n L_{\mathrm{w}}(\lambda)$ according to WSME-HR in the BPB is re-calculated for 412, 443, 488, 531, 555 and $667 \mathrm{~nm}$, corresponding to the nominal wavelengths of the visible range of MODIS scanners installed on the NASA Aqua and Terra satellites. Reduction to these wavelengths makes it convenient to compare the ocean color products obtained with these scanners. Taking into account that during the entire operation period of NASA satellites the ocean color products are validated, as a result of the comparison it is possible to draw conclusions about the quality of the products according to the Russian satellite data.

To compare the secondary WSME-HR products, the nearest time images of the Aqua, Terra, Landsat-8 satellites were selected (Tab. 1). The images are processed by the SeaDAS software developed by the NASA Ocean Biology Processing Group (OBPG) to determine ocean color products from different spectroradiometers (CZCS, SeaWiFS, MODIS, MERIS, VIIRS, OLI, etc.) $[1,11]$. Atmospheric correction is carried out according to the standard procedure [11-13], applied by NASA on an on-going basis. The aerosol parameters are selected by ten aerosol models [14] using top of the atmosphere radiance at two NIR wavelength. For MODIS images, the 748 and $869 \mathrm{~nm}$ were selected for operation, and for OLI images - the 865 and $2201 \mathrm{~nm}$. In optically complex waters, where the waterleaving radiance in the near IR range cannot be considered negligible, an optical model was used to estimate its values [15].

Characteristics of the Images Used

T able 1

\begin{tabular}{l|ll}
\hline \multicolumn{1}{c}{ Satellite/sensor } & \multicolumn{1}{c}{ Image Title } & \multicolumn{1}{c}{ Date/Time } \\
\hline Resurs-P No.1/WSME-HR & RP1.SVR.10000955508001.L2A & 2015-03-10/ 11:16 \\
Terra/MODIS & T2015069083500.L0_LAC & 2015-03-10/ 08:35 \\
Aqua/MODIS & A2015069102000.L0_LAC & 2015-03-10/ 10:20 \\
Landsat-8/OLI & LC81750292015070LGN00 & 2015-03-11/ 08:13 \\
\hline
\end{tabular}

Spatial resolution of the compared products was equal to $30 \mathrm{~m}$ for OLI sensor, $100 \mathrm{~m}$ for WSME-HR. Data of all MODIS spectral channels (Aqua and Terra) were interpolated to the $250 \mathrm{~m}$ grid. 


\section{Results and Discussion}

Fig. 2 shows the spatial distribution of the normalized water-leaving radiance $n L_{\mathrm{w}}(\lambda)$ according to the WSME-HR sensor data and the MODIS/Aqua data closest to it. The MODIS/Terra and Landsat-8 data are not given in Fig. 2, as they are similar to the spatial distribution $n L_{\mathrm{w}}(\lambda)$ according to the MODIS/Aqua data.

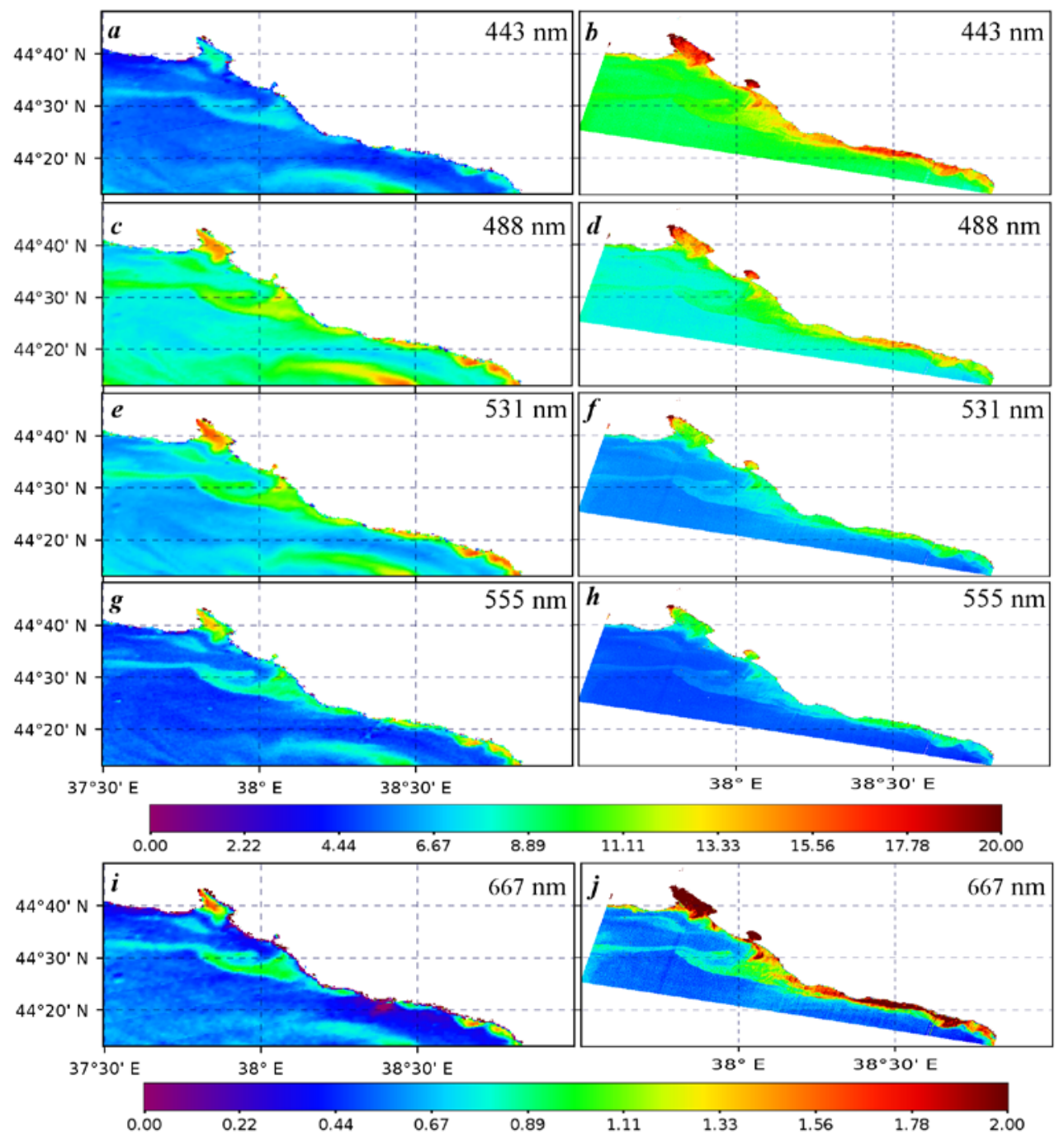

Fig. 2. Normalized water-leaving radiance $n L_{\mathrm{w}}(\lambda), \mathrm{W} /\left(\mathrm{m}^{2} \cdot \mu \mathrm{m} \cdot \mathrm{sr}\right)$ at 443, 488, 531, 555 and $667 \mathrm{~nm}$ : $a, c, e, g, i$ - according to MODIS/Aqua data; $b, d, f, h, g$ - according to WSME-HR data

At $531 \mathrm{~nm}$ the $n L_{\mathrm{w}}(531)$ values according to WSME-HR data are approximately 15-20\% smaller than those according to the MODIS data (Fig. 2, $d$, $2, e)$ and other sensors (Fig. 3, d). The area averaged $n L_{\mathrm{w}}(531)$ values (Fig. 4) are 6.8; 8; $8 \mathrm{~W} /\left(\mathrm{m}^{2} \cdot \mu \mathrm{m} \cdot \mathrm{sr}\right)$ for WSME-HR, MODIS/Aqua and MODIS/Terra, respectively. The spatial distribution of the normalized water-leaving radiance at 
$555 \mathrm{~nm}$ according to the data of all the sensors have the best agreement (Fig. 2, $g$, $3, e)$. The mean $n L_{\mathrm{w}}(555)$ values (Fig. 4) are 5.9; 6.1; 6.1; $6.2 \mathrm{~W} /\left(\mathrm{m}^{2} \cdot \mu \mathrm{m} \cdot \mathrm{sr}\right.$ ) for WSME-HR, MODIS/Aqua, MODIS/Terra and OLI, respectively.
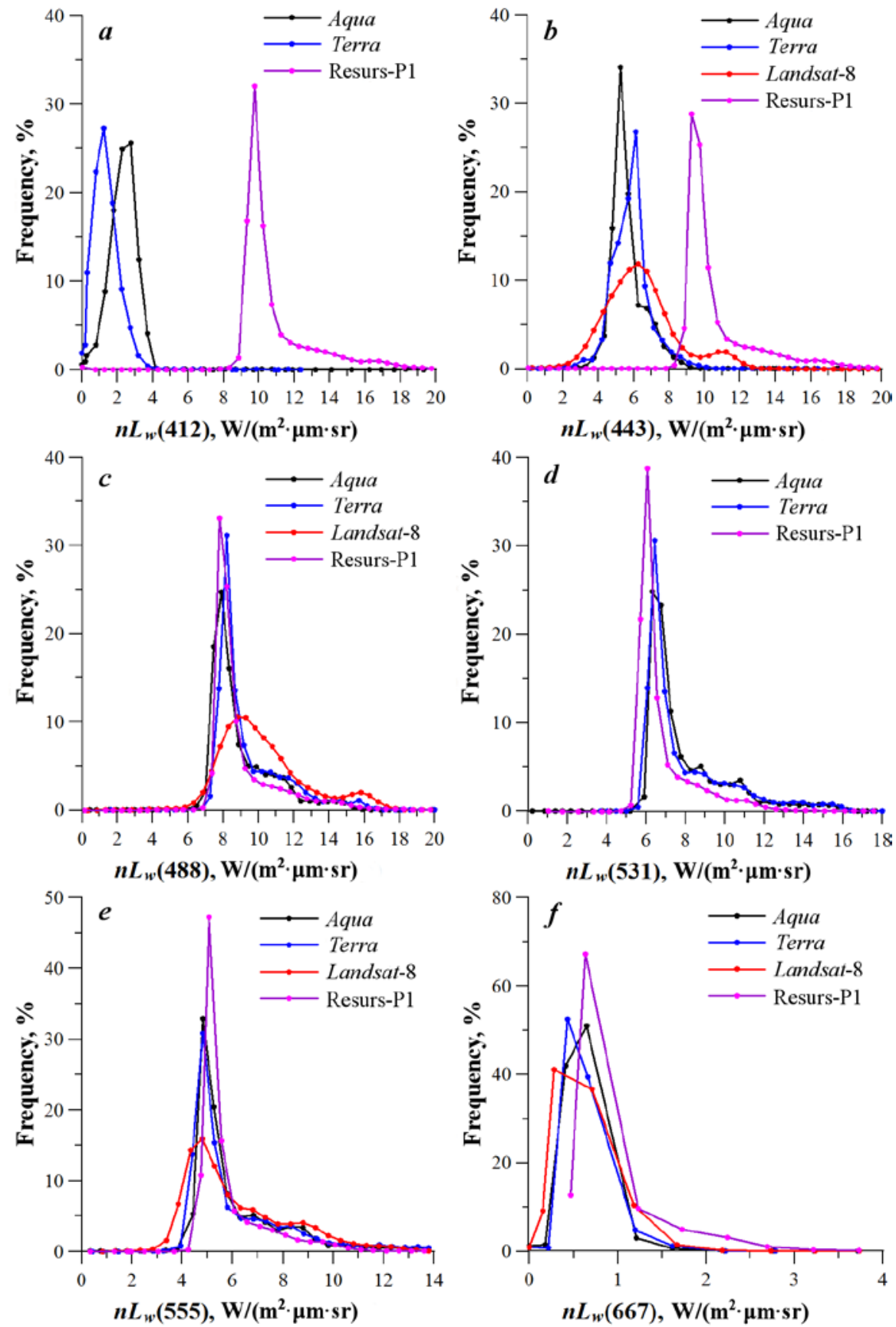

Fig. 3. The normalized water-leaving radiance $n L_{\mathrm{w}}(\lambda)$ distribution 


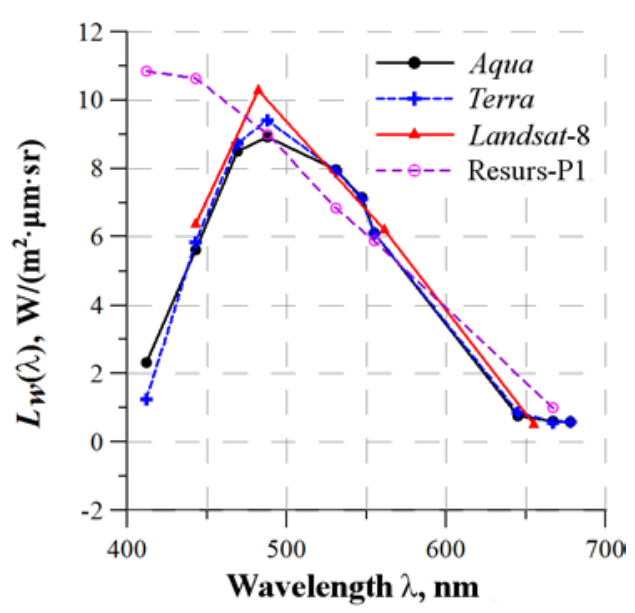

Fig. 4. Spectral normalized water-leaving radiance $n L w(\lambda)$

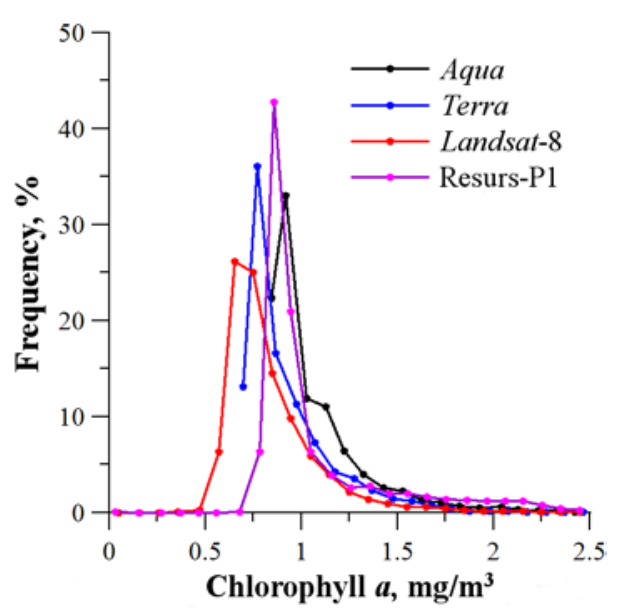

Fig. 5. Chlorophyll $a$ concentration distribution

In the red spectral range, an increase in the normalized water-leaving radiance is observed again according to the WSME-HR data relative to the data of the other sensors. As can be seen from Fig. 2, i, 2, $j$ and 3, e, the $n L_{\mathrm{w}}(667)$ values according to the WSME-HR data are approximately twice as high as $n L_{\mathrm{w}}(667)$ according to the data of foreign sensors. In the area of Tsemesskaya and Gelendzhik bays, the maximum $n L_{\mathrm{w}}(667)$ values according to the WSME-HR data are $2.5 \ldots$ $3.5 \mathrm{~W} /\left(\mathrm{m}^{2} \cdot \mu \mathrm{m} \cdot \mathrm{sr}\right.$ ) (Fig. 2, $k$ ), according to MODIS/Aqua data $0.8 \ldots$ $1.6 \mathrm{~W} /\left(\mathrm{m}^{2} \cdot \mu \mathrm{m} \cdot \mathrm{sr}\right)$. In the coastal zone, the normalized water-leaving radiance according to the WSME-HR and MODIS/Aqua data are within the range of $1.6 \ldots$ $3.0 \mathrm{~W} /\left(\mathrm{m}^{2} \cdot \mu \mathrm{m} \cdot \mathrm{sr}\right)$ and $0.5 \ldots 1.5 \mathrm{~W} /\left(\mathrm{m}^{2} \cdot \mu \mathrm{m} \cdot \mathrm{sr}\right)$, respectively. The area-averaged $\mathrm{nLw}(667)$ values are 1,$0 ; 0,6 ; 0,6 ; 0,5 \mathrm{~W} /\left(\mathrm{m}^{2} \cdot \mu \mathrm{m} \cdot \mathrm{sr}\right)$ for WSME-HR, MODIS/Aqua, MODIS/Terra and OLI images, respectively (Fig. 4).

The spectral dependences (Fig. 4) according to the data of foreign scanners correspond to the characteristic features of the normalized water-leaving radiance $n L_{\mathrm{w}}(\lambda)$ in sea waters with chlorophyll $a$ content over $0.1 \mathrm{mg} / \mathrm{m}^{3}$. In such waters, absorption maxima by the yellow substance (the phytoplankton life and decay product) and phytoplankton pigments are in the 400-450 nm range. These components of sea water absorption determine the position of the maximum of the water-leaving radiance $n L_{\mathrm{w}}(667)$ at about $460-480 \mathrm{~nm}$. In the case of very turbid waters, the maximum can shift to the green spectral range. At $400-410 \mathrm{~nm}$, the $n L_{\mathrm{w}}(\lambda)$ radiance values, mainly due to strong absorption by the yellow matter, usually make up about $40-50 \%$ of the maximum. The $n L_{\mathrm{w}}(\lambda)$ spectrum according to the WSME-HR data is typical for very pure ocean waters, the chlorophyll $a$ concentration in which does not exceed $0.05 \mathrm{mg} / \mathrm{m}^{3}$. Since the time difference between the images (except for the Landsat- 8 image) is about 2-2.5 hours, a similar behavior of the spectral dependence $n L_{\mathrm{w}}(\lambda)$ in the blue spectral range 
according to WSME-HR data should also be expected. However, the $n L_{\mathrm{w}}(\lambda)$ values at 412 and $443 \mathrm{~nm}$ not only do not decrease twice, but also show an increase with respect to the $n L_{\mathrm{w}}(488)$ value. This behavior of $n L_{\mathrm{w}}(\lambda)$ clearly contradicts the observations. It can be due both to the radiometric sensor calibration accuracy and due to the errors in the retrieval algorithms of $n L w(\lambda)$ from satellite-measured TOA radiance.

The $C_{a}$ chlorophyll $a$ concentration is calculated using the standard algorithm OC3 (OLI) and OS3M (MODIS), which uses ratio of the remote sensing reflectances $R_{r s}$ in the blue-green spectral range [7]. The frequency distribution of $C_{a}, \mathrm{mg} / \mathrm{m}^{3}$ is shown in Fig. 5, and the spatial one - in Fig. 6. As can be seen from Fig. 6, the spatial distribution of $C_{a}$ has a similar structure and comparable values for all the sensors. Minor changes in the OLI image are due to the almost diurnal difference with the rest of the images.

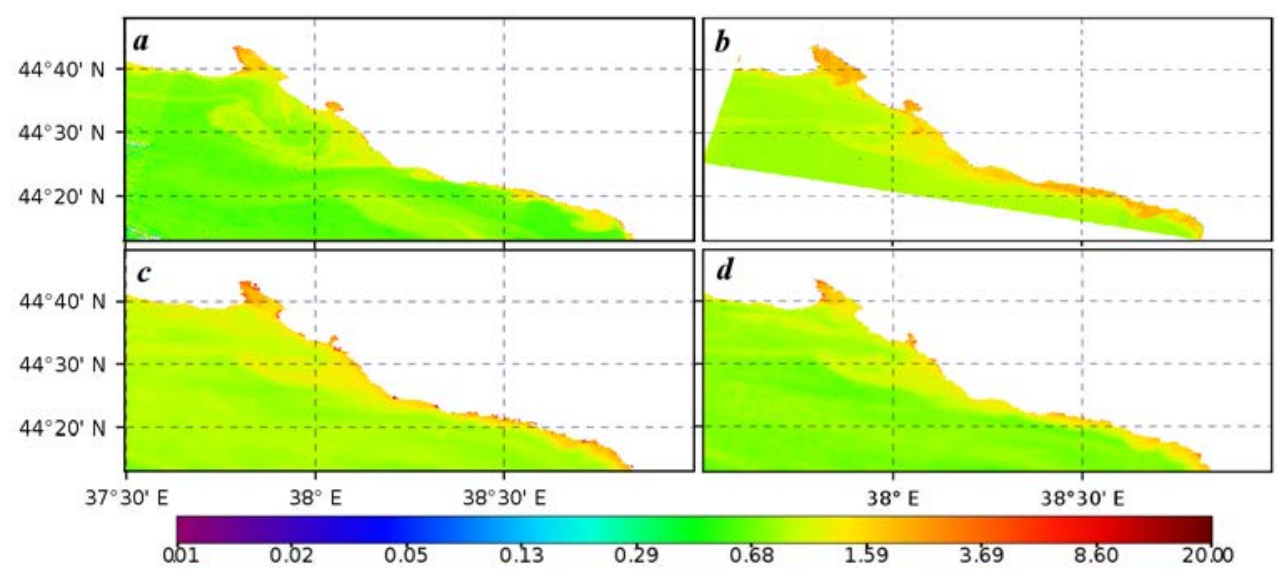

Fig. 6. Spatial distribution of chlorophyll $a$ concentration $C_{a}, \mathrm{mg} / \mathrm{m}^{3}$ according to: $a-\mathrm{OLI} ; b-$ WSME-HR; $c$-MODIS/Aqua; $d$-MODIS/Terra

The chlorophyll $a$ concentration according to the WSME-HR data is more in line with the MODIS/Aqua data. The mean $C_{a}$ values, calculated for regions of the same area images, are 1.09; 0.93; 0.85 and $1.06 \mathrm{mg} / \mathrm{m}^{3}$ for Aqua, Terra, Landsat-8 and Resurs-P, respectively. The maximum values of $C_{a}=2 \ldots 2.5 \mathrm{mg} / \mathrm{m}^{3}$ on the images of foreign satellites are localized on the part of Tsemesskaya and Gelendzhik bays and along the coasts below $44^{\circ} 25^{\prime}$ latitude. The maximum values of $C_{a}=2 \ldots 2.5 \mathrm{mg} / \mathrm{m}^{3}$ on the Russian satellite image are observed over the entire area of the bays and on the wide coastal area.

As can be seen from Fig. 5, the frequency distribution curves have a similar shape. The shift of the maximums of the curves, relative to which the area averaged values are located to the right, is no more than $30 \%$. It is also clearly visible that, according to the WSME-HR sensor, the frequency of occurrence of $C_{a}>1.6 \mathrm{mg} / \mathrm{m}^{3}$ is higher than that of other sensors. 
Thus, despite the differences in the values of the normalized radiance, the mean values of the chlorophyll $a$ concentration for the sensors analyzed are in good agreement with each other. Variations in the spatial distribution of chlorophyll $a$ in the coastal area can be explained equally by the difference between the $n L_{\mathrm{w}}(\lambda)$ values, spatial averaging and the need to correct the coefficients of the OC3M polynomial method originally selected for MODIS scanners for the WSME-HR sensor.

\section{Conclusions}

1. High spatial and temporal resolution of WSME-HR Resurs-P type satellite images makes data of their measurements attractive for solving a wide range of problems of satellite hydrophysics, in particular, investigation of optical properties of waters, their composition and bio-productivity, dynamics of the shore changes, etc.

2. Comparison of the products obtained from the image of the WSME-HR sensor of the Resurs-P No. 1 satellite with similar products of the foreign optical ocean color sensors revealed the following features. The normalized water-leaving radiation according to the WSME-HR data in the blue (412 and $443 \mathrm{~nm}$ ) and red spectral range are much higher than in the MODIS data and in the green spectral range are in good agreement with them. Estimates of chlorophyll $a$ from the data of the spectroradiometers being compared have similar values. The closeness of the results is explained by the minimal differences in the normalized water-leaving radiance values at 488 and $555 \mathrm{~nm}$, which are used to calculate chlorophyll $a$.

3. Naturally, the results of the present research are not sufficient to draw definitive conclusions about the accuracy of the WSME-HR sensor products and the possibility of using them for solving the problems of satellite hydrophysics. For this purpose, long-term observations of the entire Black Sea water area by all three satellites of the Resurs-P type are required. Unfortunately, there is not enough imagery from these satellites, and the captured scenes are not available for public access, which makes it difficult to carry out such an analysis.

\section{REFERENCES}

1. Franz, B.A., Bailey, S.W., Kuring, N.A. and Werdell, P.J., 2015. Ocean Color Measurements with the Operational Land Imager on Landsat-8: Implementation and Evaluation in SeaDAS. J. Appl. Remote Sens., [e-journal] 9(1), 096070, 16 p. doi:10.1117/1.JRS.9.096070

2. Vanhellemont, Q. and Ruddick, K., 2014. Turbid Wakes Associated with Offshore Wind Turbines Observed with Landsat-8. Remote Sens. Environ., [e-journal] 145, pp. 105-115. doi:10.1016/j.rse.2014.01.009

3. Zhang, Y., Pulliainen, J.T., Koponen, S.S. and Hallikainen, M.T., 2003. Water Quality Retrievals from Combined Landsat TM Data and ERS-2 SAR Data in the Gulf of Finland. IEEE Trans. Geosci. Remote Sens., [e-journal] 41(3), pp.622-629. doi:10.1109/TGRS.2003.808906

4. $\quad$ Pahlevan, N., Sheldon, P., Peri, F., Wei, J., Shang, Z., Sun, Q., Chen, R.F., Lee, Z., Schaaf, C.B., Schott, J.R. and Loveland, T., 2016. Calibration/Validation of Landsat-Derived Ocean Colour Products in Boston Harbour. Int. Arch. Photogramm. Remote Sens. Spatial Inf. Sci., [e-journal] XLI-B8, pp. 1165-1168. https://doi.org/10.5194/isprs-archives-XLI-B8-1165-2016 
5. Wang, J.J., Lu, X.X., Liew, S.C. and Zhou, Y., 2009. Retrieval of Suspended Sediment Concentrations in Large Turbid Rivers Using Landsat ETM+: an Example from the Yangtze River, China. Earth Surf. Process. Landforms, [e-journal] 34, pp. 1082-1092. doi:10.1002/esp.1795

6. Yu, Z., Chen, X., Zhou, B., Tian, L., Yuan, X. and Feng, L., 2012. Assessment of Total Suspended Sediment Concentrations in Poyang Lake Using HJ-1A/1B CCD Imagery. Chin. J. Ocean. Limnol., [e-journal] 30(2), pp. 295-304. http://dx.doi.org/10.1007/s00343-012-1094-y

7. Li, J., Tian, L., Chen, X., Li, X., Huang, J., Lu, J. and Feng, L., 2014. Remote-Sensing Monitoring for Spatio-Temporal Dynamics of Sand Dredging Activities at Poyang Lake in China. Int. J. Remote Sens., [e-journal] 35(16), pp.6004-6022. doi:10.1080/01431161.2014.939783

8. Vasilyev, A.I., Korshunov, A.P., Olshevskiy, N.A. and Stremov, A.S., 2015. Programnye Tehnologii Sozdaviya i Rasprostraneniya Bazovyh Produktov Distantsionnogo Zondirovaniya Zemli [Software Technologies for Generation and Distribution of Basic Earth Remote Sensing Data Products]. Rocket-Space Device Engineering and Information Systems, 2(3), pp. 23-32 (in Russian).

9. Markov, A.N., Vasilyev, A.I., Olshevskiy, N.A., Korshunov, A.P., Mikhalenkov, R.A., Salimonov, B.B. and Stremov, A.S., 2016. Arhitektura Geoinformatsionnogo Servisa Bank Bazovyh Produktov [Architecture of the Basic Product Bank Geoinformation Service]. Sovremennye Problemy Distantsionnogo Zondirovaniya Zemli iz Kosmosa [Current Problems in Remote Sensing of the Earth from Space], [e-journal] 13(5), pp. 39-51 (in Russian). doi:10.21046/2070-7401-2016-13-5-39-51

10. Baklanov, A.I., Afonin, A.N., Blinov, V.D. and Zabiyakin, A.S., 2016. KShMSA - Compleks Shirokozahvatnoy Multispektralnoy Apparatury Kosmicheskogo Apparata Resurs-P [CWSME - Complex of Wide-Swath Multispectral Equipment for the "Resource-P" Spacecraft]. Vestnik of the Samara State Aerospace University, [e-journal] 15(2), pp. 22-29 (in Russian). doi:10.18287/2412-7329-2016-15-2-22-29

11. Wang, M. ed., 2010. Atmospheric Correction for Remotely-Sensed Ocean-Colour Products (IOCCG Report Number 10). Dartmouth, Canada: International Ocean-Colour Coordinating Group, 78 p. Available at: http://ioccg.org/reports/report10.pdf [Accessed: 16 February 2018].

12. Mobley, C.D., Werdel,1 J., Franz, B., Ahmad, Z. and Bailey, S., 2016. Atmospheric Correction for Satellite Ocean Color Radiometry. Greenbelt, MD, USA: NASA Goddard Space Flight Center, 73 p. Available at: https://oceancolor.gsfc.nasa.gov/docs/technical/NASA-TM-2016217551.pdf [Accessed: 16 February 2018].

13. Ocean Biology Processing Group at NASA Goddard Flight Center. Algorithm Description of the Standard Suit of Ocean Color Products. [on-line] Available at: https://oceancolor.gsfc.nasa.gov/atbd [Accessed: 16 February 2018].

14. Ahmad, Z., Franz, B.A., McClain, C.R., Kwiatkowska, E.J., Werdell, P.J., Shettle, E.P. and Holben, B.N., 2010. New Aerosol Models for the Retrieval of Aerosol Optical Thickness and Normalized Water-Leaving Radiances from the SeaWiFS and MODIS Sensors over Coastal Regions and Open Oceans. Appl. Opt., [e-journal] 49(29), pp. 5545-5560. doi:10.1364/AO.49.005545

15. Bailey, S.W., Franz, B.A. and Werdell, P.J., 2010. Estimation of Near-Infrared Water-Leaving Reflectance for Satellite Ocean Color Data Processing. Optics Express, [e-journal] 18(7), pp. 7521-7527. doi:10.1364/OE.18.007521

\section{About the author:}

Sergey V. Fedorov - Senior Research Associate, Remote Sensing Department, FSBSI MHI (Sevastopol, Russian Federation), Ph.D. (Tech.), ORCID ID: 0000-0001-7716-7456, s.fedorov@mhi-ras.ru.

The author has read and approved the final manuscript.

The author declares that he has no conflict of interest. 